\title{
Persistent surface snowmelt over Antarctica (1987-2006) from 19.35 GHz brightness temperatures
}

\author{
M. Tedesco, ${ }^{1,2}$ W. Abdalati, ${ }^{2}$ and H. J. Zwally ${ }^{2}$ \\ Received 2 July 2007; revised 11 August 2007; accepted 27 August 2007; published 22 September 2007.
}

[1] Persistent melting (e.g., continuing for more than three days or for one consecutive day and night) is mapped in Antarctica (1987-2006) using night- and day-time Special Sensor Microwave Imager brightness temperatures $(\mathrm{Tb})$ at 19.35 GHz, horizontal polarization. Snowmelt is indicated when $\mathrm{Tb}$ and relative daily difference exceed threshold values, respectively $T c$ and $\Delta T$, computed for each pixel and year, or when both daytime and nighttime $\mathrm{Tb}$ exceed $T c$. Results from an electromagnetic model suggest that the minimum detectable liquid water content ranges between 0.2 and $0.5 \%$, in volume. We find that melting areas have been moving inland since 1987. A first-time extensive melting (1987-2006) is detected over the Transantarctic Mountains on January 2005, $875 \mathrm{Km}$ inland and $2000 \mathrm{~m}$ above sea level. Melting extent and index have been decreasing over Antarctica, since 1987, although either positive and negative trends are observed from a subcontinental scale analysis. Citation: Tedesco, M., W. Abdalati, and H. J. Zwally (2007), Persistent surface snowmelt over Antarctica (1987-2006) from $19.35 \mathrm{GHz}$ brightness temperatures, Geophys. Res. Lett., 34, L18504, doi:10.1029/2007GL031199.

\section{Introduction}

[2] Recent studies reported rise of surface temperatures in Antarctica [e.g., Jacobs and Comiso, 1997; Skvarca et al., 1998] as well as cooling [e.g., Comiso, 2000]. The strong positive correlation with the near surface air temperature and the melting index [e.g., Liu et al., 2006] suggests that the latter can be used as an indicator of changing climate. In this paper, we update the results of previous investigations by studying the presence of persistent melting in Antarctica between 1987 and 2006 by means of a more sensitive method, using nighttime and daytime microwave brightness temperatures at $19.35 \mathrm{GHz}$, horizontal polarization. Microwave data are measured by the Special Sensor Microwave Imager radiometer (SSM/I), flying onboard the F-08, F-11 and F-13 satellites of the Defense Meteorological Satellite Program (DMSP). We classify persisting melting areas as those where melting continued for more than three days or for one consecutive day and night. We chose the $19.35 \mathrm{GHz}$ frequency, instead of others also available from SSM/I (e.g., $37 \mathrm{GHz}$ ), for two reasons: first, data measured at $37 \mathrm{GHz}$ are more influenced by fluctuations of surface parameters (e.g., grain size) than 19.35 GHz data; second we observed that, in agreement with

\footnotetext{
${ }^{1}$ Joint Center for Earth Systems Technology, University of Maryland, Baltimore County, Baltimore, Maryland, USA.

${ }^{2}$ NASA Goddard Space Flight Center, Greenbelt, Maryland, USA.
}

Copyright 2007 by the American Geophysical Union. 0094-8276/07/2007GL031199 other studies [e.g., Liu et al., 2006; Tedesco, 2007], brightness temperature at $19.35 \mathrm{GHz}$, horizontal polarization shows the largest difference between melt onset and dry snow conditions, hence providing more sensitivity to melting events.

\section{Background and Rationale}

[3] Zwally and Fiegles [1994] and Mote et al. [1995] used similar approaches to derive snowmelt extent over Antarctica and Greenland from passive microwave brightness temperatures. The common idea behind these two approaches is using the difference between the daily brightness temperature $(\mathrm{Tb})$ and a mean brightness temperature $(\mathrm{Tm})$ : if the difference $(\mathrm{Tb}-\mathrm{Tm})$ is greater than a fixed threshold (Tc), then snow is classified as wet. Mote et al. [1995] used microwave-emission model simulations at $37 \mathrm{GHz}$ to derive threshold values, with the reference brightness temperature being the mean of the brightness temperature values collected during winter. The value of Tm used in the study reported by Zwally and Fiegles [1994] consists of the mean annual brightness temperature with the threshold value derived as the sum of Tm and a fixed value of $30 \mathrm{~K}$. More recently, Torinesi et al. [2003] used an approach similar to the one proposed by Zwally and Fiegles [1994], except that the threshold value Tc was obtained as the sum of the annual mean Tm plus $\mathrm{N}$ times the standard deviation of brightness temperatures. This process was repeated for each season and for each pixel, with the value of $\mathrm{N}$ fixed to 3, for all pixels and years [Torinesi et al., 2003]. Updated results are also reported by Picard et al. [2007]. In a recent study, Nghiem et al. [2007] used data measured by the NASA Quick Scatterometer (QuikSCAT) for detecting melting events over the Antarctica ice sheet and identified melting events where melt had been considered unlikely (e.g., far inland, at high latitudes and at high elevations) for the first time during the study period (1999-2005). Nevertheless, the major limitation of the study by Nghiem et al. [2007] is related to the short-term analysis driven by the limitation of QuikSCAT data. It should also be noted that active sensors are highly sensitive to the presence of very small amount of liquid water within the snowpack, whereas passive sensors tend to require higher values of liquid water content to detect melting. The basic ideas used by Zwally and Fiegles [1994] and Torinesi [2003] are herein combined with the use of diurnal amplitude variations (DAV) in an algorithm that uses dynamic threshold values (in both space and time) for the detection of persistent melting events.

\section{Data and Techniques}

[4] We use NOAA/NASA Pathfinder SSM/I Level 3 EASE-Grid brightness temperature data measured by SSM/I 


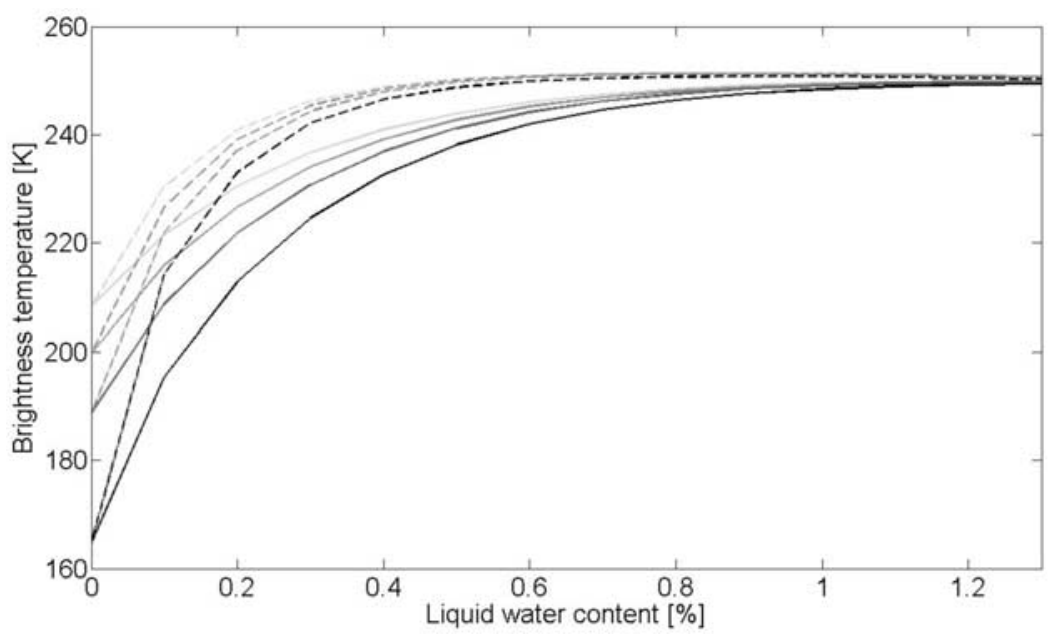

Figure 1. Modeled brightness temperatures at $19.35 \mathrm{GHz}$, horizontal polarization vs. liquid water content when the wet layer is $5 \mathrm{~cm}$ (solid line) or $10 \mathrm{~cm}$ (dashed line) thick.

mounted on the DMSP F-08 (1988-1992), F-11 (1992-1995) and F-13 (1995-2006) platforms [Armstrong et al., 1994]. Data are daily, with a resolution of $25 \mathrm{Km}$ and separated into ascending and descending passes. Further information about the product can be found at http://nsidc.org/data/docs/daac/ nsidc0032_ssmi_ease_tbs.gd.html.

[5] Our wet-snow algorithm is the following: for each pixel and year, we compute the threshold value Tc as the sum of the mean winter temperature (Tm) plus a $\Delta \mathrm{T}$ that is equal to $3 \sigma$, giving $\mathrm{Tc}=\mathrm{Tm}+\Delta \mathrm{T}$ where $\sigma$ is the standard deviation of brightness temperatures, as given by Torinesi et al. [2003]. If either the ascending or descending Tb exceeds the threshold Tc and the difference between daytime and nighttime is greater than $\Delta \mathrm{T}$, then the pixel area is classified as melting. If $3 \sigma$ is less than $30 \mathrm{~K}$, then $\Delta \mathrm{T}$ is set to $30 \mathrm{~K}$. The reason of this choice is explained in the following paragraph. We use the additional rule that classifies snow as melting when both ascending and descending measured $\mathrm{Tb}$ exceed the threshold value Tc, to account for melting persisting between nighttime and daytime acquisitions.

[6] From the analysis of mean brightness temperature Tm and standard deviation values $\sigma_{m}$, we note that some of the values of standard deviation for internal areas range be- tween 2 and $5 \mathrm{~K}$ while they can exceed 7-10 K for coastal areas. Hence, using the approach of Torinesi et al. [2003], $\Delta \mathrm{T}$ values for internal areas would range between 6 and $15 \mathrm{~K}\left(3 \sigma_{m}\right)$. A detailed analysis of the temporal evolution of brightness temperatures for internal areas indicates that the threshold value derived using this approach might be related to wetness values which are too low to be associated with persistent melting. On the other hand, the coastal values of the relative increase in the brightness temperature are very close to the fixed value proposed by Zwally and Fiegles [1994] (30 K) and Tedesco [2007] for Greenland (25 K). As a consequence of these considerations, we set $\Delta \mathrm{T}=30 \mathrm{~K}$ when $3 \sigma$ does not exceed $30 \mathrm{~K}$.

[7] In order to study the sensitivity of the proposed algorithm to the presence of liquid water and to better understand the selection of the threshold values, we conduct an analysis based on the results of an electromagnetic model. The Microwave Emission Model Multi-layered Snowpacks (MEMLS) [e.g., Matzler and Wiesmann, 1999] is used to study the behavior of $\mathrm{Tb}$ as a function of wetness for different snow conditions. The inputs to the electromagnetic model are derived assuming that snow parameters evolve along the vertical depth as exponential

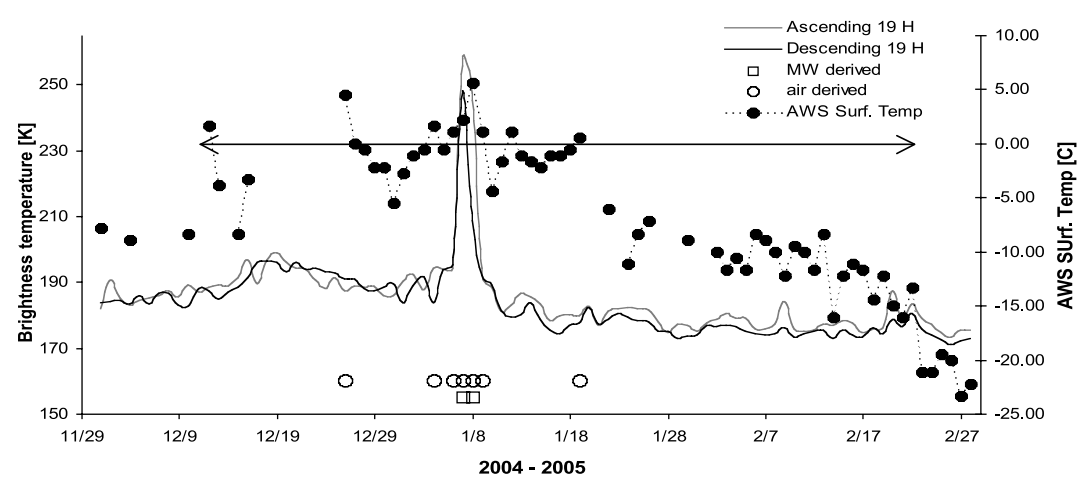

Figure 2. Ascending (gray line) and descending (black line) brightness temperatures at $19.35 \mathrm{GHz}$, horizontal polarization (left axis), air temperature (dashed line with black circles, right axis) measured at the Lettau station $\left(82.6^{\circ} \mathrm{S}, 174.3^{\circ} \mathrm{W}\right)$. The horizontal line shows the $0^{\circ} \mathrm{C}$ line. Open circles show the days when melting was detected assuming air temperature exceeding $0^{\circ} \mathrm{C}$, where open squares show the persistent melting events identified with the algorithm proposed in this study. 

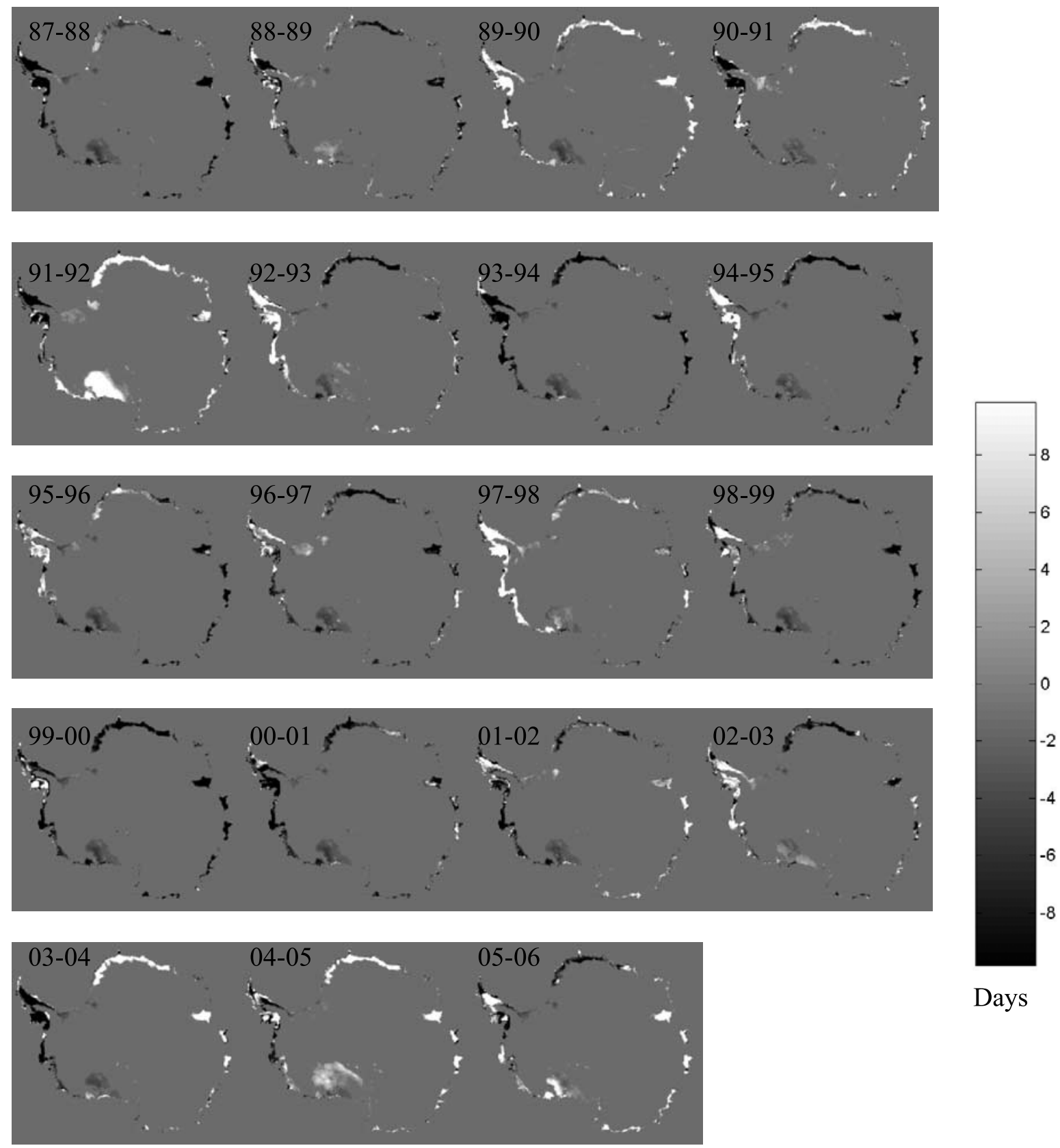

Days

Figure 3. Surface snowmelt anomaly maps (e.g., difference between the number of melting days and the average number of melting days for the period 1987-2006) for the seasons between 1987 and 2005.

functions of depth [e.g., Tedesco et al., 2003]. By changing the values of snow parameters at the surface, it is possible to simulate snow conditions with different vertical profiles. The analysis of the results (Figure 1) suggests that an algorithm with a dynamic threshold (as used here) is sensitive to different values of liquid water content, depending on dry snow $\mathrm{Tb}$ values. For example, an increase of $30 \mathrm{~K}$ is a consequence of liquid water content values below $0.2 \%$ when dry snow brightness temperature is below $150 \mathrm{~K}$, between 0.2 and $0.3 \%$ in the case of dry snow $\mathrm{Tb}$ values around $200 \mathrm{~K}$, and between $0.35 \%$ and $0.45 \%$ when dry snow $\mathrm{Tb}$ are above $210 \mathrm{~K}$. From Figure 1, it also follows that the choice of a low value for $\Delta \mathrm{T}$ is sensitive to the presence of very small liquid water contents. We prefer to exclude these melting events as we are more interested in studying those cases when persistent and significant melting occurs.

[8] Similar algorithms have been validated by showing the relation between indications of melting and air temperatures that would cause melting [e.g., Torinesi et al., 2003; Zwally and Fiegles, 1994]. Figure 2 shows the time series of ascending (gray line) and descending $\mathrm{Tb}$ (black line) brightness temperatures at $19.35 \mathrm{GHz}$, horizontal polarization (left axis), and air temperature (dashed line with black circles, right axis) measured at the Lettau station $\left(82.6^{\circ} \mathrm{S}\right.$, $\left.174.3^{\circ} \mathrm{W}\right)$. Also shown are the days when the air temperature exceeded $0^{\circ} \mathrm{C}$ (open circles) and melting should have occurred along with the persisting melting events identified 


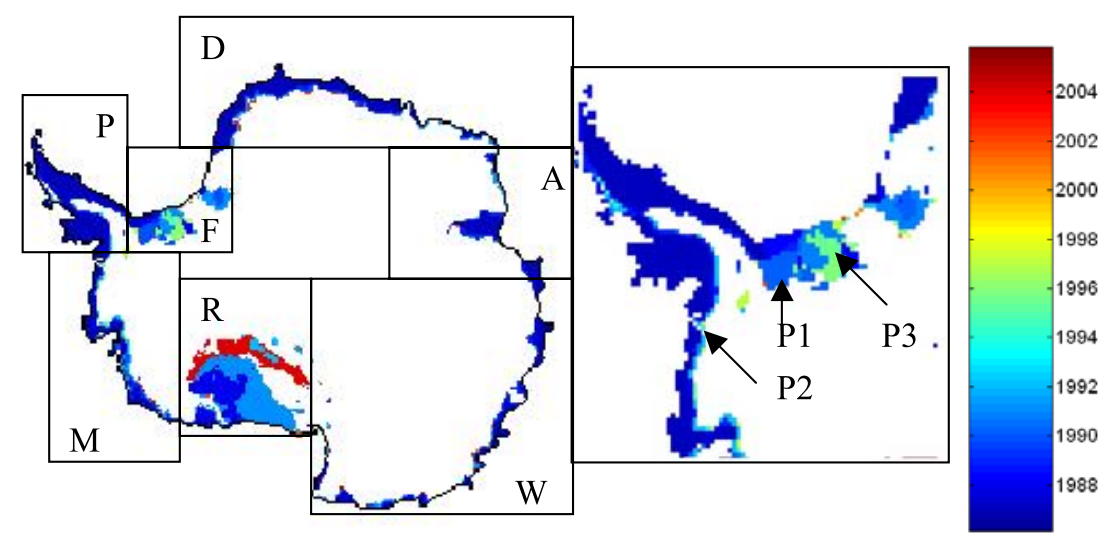

(a)

(b)

Figure 4. Map showing the year when first time persisting melting was detected within the study period (1987-2006) for the Peninsula (P), Filchner (F), Dronning Maud Land (D), Amery (A), Wilkes (W), Ross (R), and Marie Byrd Land (M) zones.

by our algorithm (open squares). The results indicate that the algorithm detects melting only when more than three days of melting occur, without including sporadic shorterterm melting events.

\section{Results and Discussion}

[9] Figure 3 shows melting anomaly maps (e.g., the difference between the number of melting days for a given year and the average number of melting days) for the period 1987-2006. During the season 1989-1990, most of the coastal areas in Antarctica were subject to melting for a high number of days (above 60 days on the Palmer Land facing the Bellinghausen sea). Then, during the season 19911992, the Ross Ice Shelf was also subject to extensive melting that lasted for more than 30 days. The area affected by melting around the ice shelf was approximately $508,750 \mathrm{Km}^{2}$ with a melting index (melting area times duration) of $7,020,625 \mathrm{Km}^{2} \times$ day. During the same season, most of the coastal areas experienced melting for more than 10 days above the average, with the exception of the coasts surrounded by the Weddell and Bellinghausen seas (differently from the season 1989-1990). During the 1997-1998 season, most of the coastal areas were subject to melting for a number of days above the average (positive anomaly), although for less days than those observed during the 1991-1992 season. In 1997, unlike 1991, persistent melting occurred along the Peninsula and its interior. Melting also occurred on the Ross Ice Shelf area, with a melting index of $1,284,375 \mathrm{Km}^{2} \times$ day and extent of $135,000 \mathrm{Km}^{2}$. During the 2004-2005 season, the Ross ice shelf was subject to melting even for inland areas and reaching the Transantarctic Mountains for the first time within the study period. The melting duration over the Ross Ice Shelf in 2004-2005 was shorter than that observed in 1991-1992, with a melting index of $3,143,750 \mathrm{Km}^{2} \times$ day. Melt extent during the 2004-2005 season over the Ross Shelf zone reached $437,500 \mathrm{Km}^{2}$, close to that observed in 1991-1992, but distributed differently and involving internal areas.

[10] Figure 4 shows the years when persisting melting was detected for the first time within the study period.
Antarctica is divided into seven zones: Peninsula (P), Filchner (F), Dronning Maud Land (D), Amery (A), Wilkes (W), Ross (R), and Marie Byrd Land (M). These will be used in the following section for analysis of long-term trends of melting extent and index. From Figure 4, we see that most of the areas along the coasts experienced melting for the first time in 1987. However, some areas along the coast experienced persistent melting for the first time in the seasons of 1990 (Figure 4, right, P1), 1992 (P2) and 1996 (P3). Note that the 1991-1992 season was also the first one during the study period when extensive melting occurred over the Ross Ice Shelf. Interestingly, over the Transantarctic Mountains and on the edge of the Ross Ice Shelf, an extensive $\left(168,750 \mathrm{Km}^{2}\right)$ persistent week-long melting occurred continuously between January 6-12, 2005, for the first time in 18 years. For this period, melting occurred for areas located up to $875 \mathrm{Km}$ inland and $2000 \mathrm{~m}$ above sea level. These results are consistent with those derived from QuikSCAT data for the overlapping periods [Nghiem et al., 2007]. Figure 5 shows temporal trends of melt extent (dashed line) and melting index (solid line) between 1987 and 2006 for the seven zones of Figure 4 and regression coefficients from linear fitting. Results indicate that, over the whole Antarctica, both melt extent and index have been decreasing since 1987 at a rate of $-2,412 \mathrm{Km}^{2} /$ year and $-34,567\left(\mathrm{Km}^{2} *\right.$ day $) /$ year, respectively. Nevertheless, considering the different zones separately, we observe both positive and negative trends. The Peninsula (P), Filchner (F), Dronning Maud Land (D), and Marie Byrd Land (M) zones are subject to a decrease on both melt extent and melting index, with the Filchner and Dronning Maud Land zones showing a similar decrease on melt extent (respectively, $-1,955$ and $-2,412 \mathrm{Km}^{2} /$ year), followed by the Peninsula zone $\left(-1,128 \mathrm{Km}^{2} /\right.$ year $)$. Marie Byrd Land is the zone showing the smallest decrease on melt extent with $-762 \mathrm{Km}^{2} /$ year, but the highest melting index $(-41,783$ $\mathrm{Km}^{2} *$ day/year), hence suggesting that the number of days when melting occurred has been decreasing since 1987, followed by Dronning Maud Land $\left(-33,000\left(\mathrm{Km}^{2} *\right.\right.$ day $) /$ year), Peninsula $\left(-22,767\left(\mathrm{Km}^{2} *\right.\right.$ day $) /$ year $)$ and Filchner 


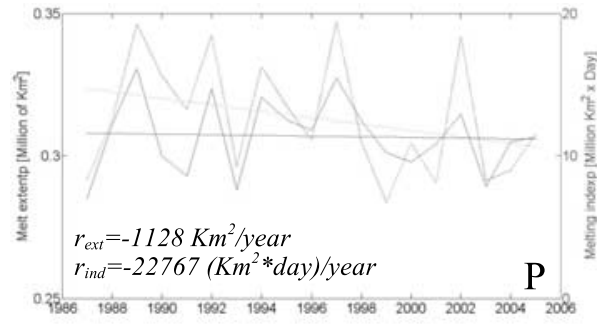

(a)

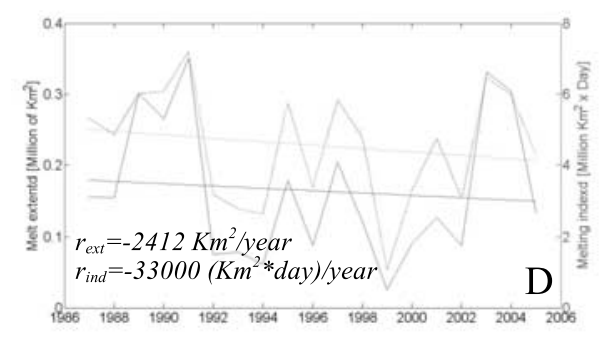

(c)

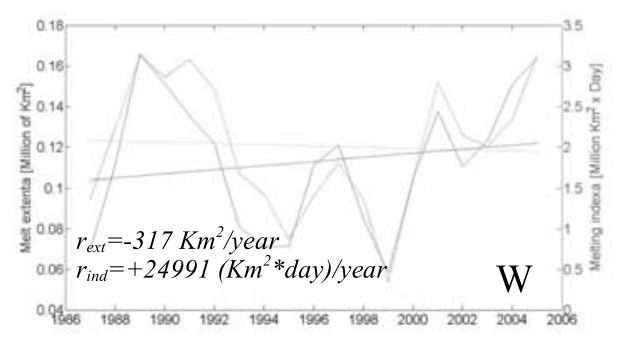

(e)

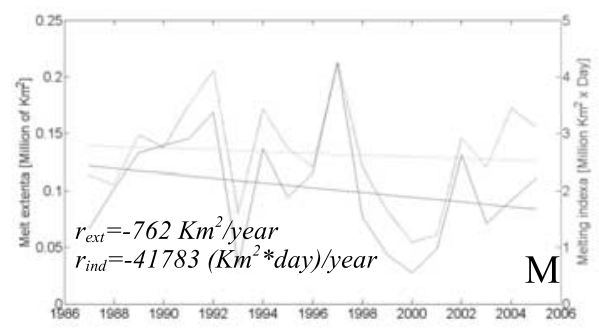

(g)

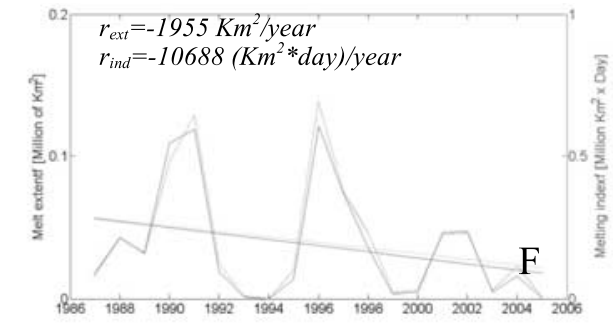

(b)

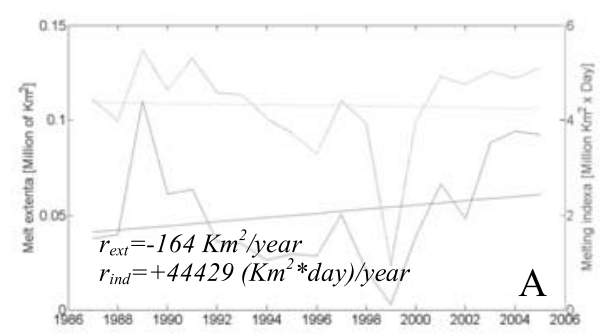

(d)

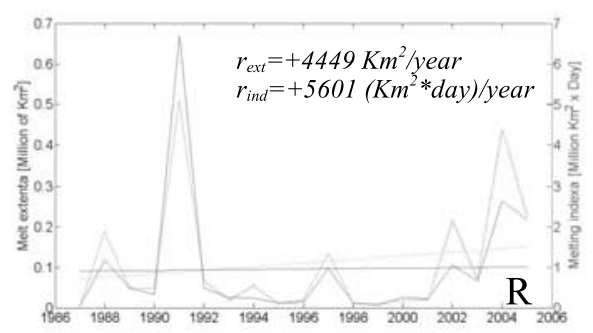

(f)

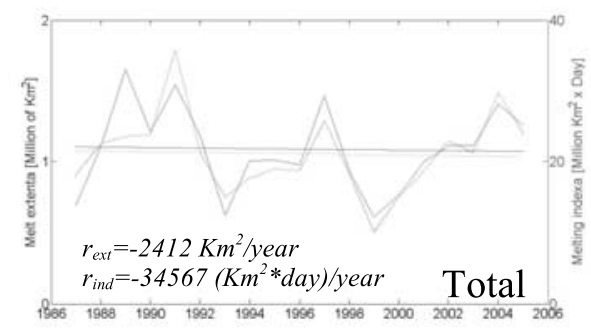

(h)

Figure 5. Melt extent (dashed line) and melting index (solid line) for (a) Peninsula, (b) Filchner, (c) Dronning Maud Land, (d) Amery, (e) Wilkes, (f) Ross, (g) Marie Byrd Land zones, and (h) for the whole Antarctica. Regression coefficients from linear fitting for extent $\left(\mathrm{r}_{\mathrm{ext}}\right)$ and melting index $\left(\mathrm{r}_{\text {ind }}\right)$ are also reported.

$\left(-10,688\left(\mathrm{Km}^{2} *\right.\right.$ day)/year). The Ross zone shows an increase on both melt extent $\left(4,449 \mathrm{Km}^{2} *\right.$ day) and melting index $\left(5,601\left(\mathrm{Km}^{2} *\right.\right.$ day $) /$ year $)$. Lastly, the Amery and Wilkes zones show a slight decrease on the melt extent $\left(-164 \mathrm{Km}^{2} /\right.$ year in the case of Amery and $-317 \mathrm{Km}^{2} /$ year for Wilkes) but a more considerable increase on the melting index, respectively, 44,429 $\left(\mathrm{Km}^{2} *\right.$ day)/year for Amery and 24,991 $\left(\mathrm{Km}^{2} *\right.$ day)/year for Wilkes. This result suggests that the number of days when melting occurs on the Ross, Amery and Wilkes zones has been increasing since 1987.

\section{Conclusions}

[11] We investigate the presence of persistent melting over Antarctica between 1987 and 2006 by using both ascending and descending $\mathrm{Tb}$ at $19.35 \mathrm{GHz}$, horizontal polarization. Threshold values of $\mathrm{Tb}$ and relative daily variation are derived for each pixel and each year. Results of a multi-layer electromagnetic model suggest that the amount of liquid water content to which the algorithm is sensitive ranges between 0.2 and $0.5 \%$, in volume. The algorithm is validated over a location in Antarctica by using ground measured air temperature.

[12] Analysis of the time series of when persistent melting was observed for the first time shows that most of the areas along the coasts experienced melting as early as the first year of this record (1987). However, we also observe that unprecedented melting occurred either along the coast or inland, suggesting that melting has been moving inland since 1987. During the 1991-1992 season, extensive persistent melting was detected over the Ross Ice Shelf for the 
first time. Also, first-time extensive melting occurred over the Transantarctic Mountains and on the edge of the Ross Ice Shelf for the week between January 6-12, 2005, with melting reaching areas located $875 \mathrm{Km}$ inland and $2000 \mathrm{~m}$ above seal level.

[13] Analysis of melting anomalies shows that during the season 1989-1990, most of the coastal areas were subject to melting for a high number of days. Also, during the seasons 1991-1992 and 1997-1998 positive anomalies (e.g., number of melting days above the average for the period 1987-2006) occurred along most of the coasts and on the Ross Ice Shelf zone. However, in contrast to 1991, persistent melting occurred in 1997 also along the Peninsula and in its interior. The 1991-1992 season was also the first occurrence of extensive persistent melting on the Ross Ice Shelf.

[14] Both melt extent and melting index have been decreasing over the whole continent since 1987. However, a sub-continental scale analysis identifies areas with increasing and decreasing trends. We identify four zones (Peninsula, Filchner, Dronning Maud Land and Marie Byrd Land) where both melt extent and melting index have been decreasing since 1987, two zones (Amery and Wilkes) where melt extent trend has been slightly decreasing but melting index has been considerably increasing, and one zone (Ross Ice Shelf) where both melt extent and melting index have been considerably increasing.

[15] Acknowledgments. We would to thank Robert Bindschadler, NASA, for his suggestions and discussions. This work was supported by the NASA Cryospheric Sciences Program.

\section{References}

Armstrong, R. L., K. W. Knowles, M. J. Brodzik, and M. A. Hardman (1994), DMSP SSM/I Pathfinder daily EASE-Grid brightness tempera- tures, 1987-2005, http://nsidc.org/data/docs/daac/nsidc0032 ssmi ease tbs.gd.html, Natl. Snow and Ice Data Cent. DAAC, Boulder, ColoComiso, J. C. (2000), Variability and trends in Antarctic surface temperatures from in situ and satellite infrared measurements, J. Clim., 13, $1674-1696$.

Jacobs, S. S., and J. C. Comiso (1997), A climate anomaly in the Amundsen and Bellingshausen seas, J. Clim., 10, 697-711.

Liu, H., L. Wang, and K. C. Jezek (2006), Spatiotemporal variations of snowmelt in Antarctica derived from satellite scanning multichannel microwave radiometer and Special Sensor Microwave Imager data (19782004), J. Geophys. Res., 111, F01003, doi:10.1029/2005JF000318.

Matzler, C., and A. Wiesmann (1999), Extension of the microwave emission model of layered snowpacks to coarse-grained snow, Remote Sens. Environ., 70(3), 307-316.

Mote, T. L., M. R. Anderson, K. C. Kuivenen, and C. M. Rowe (1995), Variations in snowpack melt on the Greenland ice sheet based on passivemicrowave measurements, J. Glaciol., 41, 51-60.

Nghiem, S. V., K. Steffen, G. Neumann, and R. Huff (2007), Snow accumulation and snowmelt monitoring in Greenland and Antarctica, in $D y$ namic Planet: Monitoring and Understanding a Dynamic Planet With Geodetic and Oceanographic Tools, edited by C. Rizos and P. Tregoning, pp. 31-38, Springer, New York.

Picard, G., M. Fily, and H. Gallee (2007), Surface melting derived from microwave radiometers as a climatic indicator in Antarctica, Ann. Glaciol., 46, 29-34.

Skvarca, P., W. Rack, H. Rott, and T. Ibarzábal y Donangelo (1998), Evidence of recent climatic warming on the eastern Antarctica Peninsula, Ann. Glaciol., 27, 628-632.

Tedesco, M., G. Macelloni, and P. Pampaloni (2003), A study on DOME-C, Antarctic: Stratigraphy and electromagnetic modeling, Rep. RR/OST/ 10.03, Ist. di Fis. Appl. Carrara, Carrara, Italy.

Tedesco, M. (2007), Snowmelt detection over the Greenland ice sheet from SSM/I brightness temperature daily variations, Geophys. Res. Lett., 34, L02504, doi:10.1029/2006GL028466.

Torinesi, O., M. Fily, and C. Genthon (2003), Interannual variability and trend of the Antarctic summer melting period from 20 years of spaceborne microwave data, J. Clim., 16, 1047-1060.

Zwally, H. J., and S. Fiegles (1994), Extent and duration of Antarctic surface melting, J. Glaciol., 40, 463-476.

W. Abdalati, M. Tedesco, and H. J. Zwally, NASA Goddard Space Flight Center, Code 614.6, Greenbelt, MD 20771, USA. (mtedesco@umbc.edu) 